\title{
SUPERVIVENCIAS ACTUALES DEL BAILE DE LA CONQUISTA EN GUATEMALA
}

POR

\author{
DEMETRIO BRISSET
}

Málaga

Proceden estos bailes de las representaciones teatrales que los misioneros introdujeron en los pueblos de indios para explicar, por medio del baile y un argumento, el proceso de la Conquista. Aún perviven en Guatemala, recogiéndose aqui material de información oral de las danzas realizadas en los últimos años, en comunidades cakchiquel, tzutuhil y quiché.

Entre los espectáculos populares que se realizan durante las fiestas patronales de las comunidades españolas y latinoamericanas, uno de los más difundidos es el de las representaciones teatrales ritualizadas. Y dentro de ellas, las de conquista son las más complejas y unas de las más interesantes desde el punto de vista antropológico.

En esencia, las representaciones rituales de conquista expresan la lucha entre un bando de héroes y otro de enemigos por el dominio de un bien colectivo, mediante acciones y parlamentos, aunque se puede prescindir de la palabra. Los bandos en lucha con mayor presencia son los de los cristianos (en rigor, católicos) y los moros (generalmente musulmanes, entre los que se suelen confundir turcos, árabes e hispanos, aunque pueden designar también a los infieles, gentiles o paganos, encarnación genérica del mal y de los enemigos ancestrales). A veces, los dos bandos antagónicos encarnan seres legendarios (ángeles, demonios, dragones), fenómenos naturales (verano, invierno), elementos de una cacería (cazadores, osos) o a los miembros de dos comunidades limítrofes. En otras ocasiones, el enfrentamiento ritual se produce entre dos nacionalidades: españoles contra portugueses, ingleses o franceses; mexicanos contra franceses; romanos contra judíos; 
griegos contra troyanos. Y en varias zonas de América, el conflicto se produce entre los invasores españoles cristianos y los aborígenes, rememorando los episodios de la Conquista.

Esta última variedad del universo festivo constituido por los rituales de conquista, es el que nos interesa destacar ahora. Son varios los investigadores que han puesto de relieve el alto grado de historicidad de sus argumentos y su función informativa sobre la "visión de los vencidos». Estas obras de teatro del folklore indígena actual, «que hacen revivir los acontecimientos del tiempo de la conquista", son para Wachtel una fuente histórica que permite conocer la visión de su derrota desde dentro del propio grupo indígena (1), mientras que para León-Portilla son «memoria profundamente humana del trauma de los vencidos", pues que su continuada representación hasta la fecha prueban que el alma indígena no ha olvidado aún lo que significó para ellos la Conquista (2).

\section{DisTRIBUCión GEOGRÁFICA DE LOS BAILES DE LA CONQUISTA}

Geográficamente, se pueden distribuir las llamadas danzas o bailes de la conquista en tres grandes grupos o ciclos temáticos:

\subsection{Ciclo Inca}

En el imperio incaico estaba extendida la afición al teatro ritual, tal como se desprende de las crónicas de Sarmiento de Gamboa, quien cuenta que Pachacuti Inga Yupangui «mandó hacer grandes fiestas y representaciones de la vida de cada inga", y de Garcilaso de la Vega, quien recuerda que en los pueblos peruanos se «solían representar comedias en tiempos de sus Reyes Incas" con sus argumentos centrados en las "proezas y glorias de soberanos y héroes pasados" (3). De la primera etapa colonial data la referencia más antigua que he encontrado sobre una representación dialogada de los acontecimientos de la conquista de América: En 1555, en la villa de Potosí se representó la

(1) Nathan WACHTEL: Los vencidos: los indios del Perú frente a la conquista española (1530-1570), Madrid, Alianza Universidad, 1976, págs. 45-49.

(2) Miguel LeÓN-PoRTILla: El reverso de la conquista (Relaciones aztecas, mayas e incas. México. Joaquín Mortiz, 1964, págs. 130-1.

(3) Clemente H. BALmORI: La conquista de los españoles y el teatro indígena americano, Argentina, Universidad Nacional de Tucumán, 1955, págs. 23-24 y 40. 
Ruina del Imperio Ingal con la entrada de los españoles, que mostraba «la prisión injusta que hicieron de Atahualpa; los presagios y admirables señales que en el Cielo y Aire se vieron antes que le quitasen la vida; tiranías y lástimas que ejecutaron los españoles en los Indios; la máquina de oro y plata que ofreció porque no le quitasen la vida, y muerte que le dieron en Caxamarca" (4).

En nuestra época se sigue representando la derrota de los incas en Potosí, con unos parlamentos bilingües (español arcaico/quechúa boliviano) y en Oruro, durante los carnavales. Otras localidades de Bolivia, donde hasta hace poco se efectuaban, son Cochabamba (con dos diablos manteniendo al público a distancia) y la misma capital, La Paz, donde la obra terminaba con la resurrección y triunfo de Atahualpa (5).

Respecto al Perú, sus dos representaciones más conocidas eran la de Chayanta, titulada Tragedia del fin de Atau Wallpa, y San Pedro de Naván, que incluía el "pago» que ofrecían el Inca y las Pallas, ahora, mozas adornadas con joyas, a los «abuelos» en el parque, ganando así su protección para que no «ocurran líos, accidentes, desgracias, enfermedades, pestes o plagas a las personas, animales y plantas de la comunidad" (6).

\subsection{Ciclo Azteca}

Se sabe que en 1595, en la fiesta del Corpus Christi de la ciudad de México, los comisarios gastaron 600 pesos en la «comedia de la conquista»: "También por aquellas fechas el Ayuntamiento construía tablados para la presentación de "conquistas" o "farsas de guerra" que parecen introducidas desde tiempo atrás» (7).

Por ser las representaciones de la lucha entre Cortés y Moctezuma las más estudiadas, apenas las trataré. Me limitaré a señalar que en algunas localidades la obra termina actualmente con la derrota parcial de los españoles en la Noche Triste, o con una distorsionada victoria final de Moctezuma sobre el conquistador extremeño. Los mayores núcleos de difusión de esta danza en

(4) Ibidem, págs. 49-50.

(5) Ibidem, págs. 44-47.

(6) Mery M. MEndez: "Las Pallas", Cuadernos del taller de folklore, Lima, Universidad Nacional "Federico Villarréal", 1980, págs. 20-21.

(7) Arturo Warman: La danza de moros y cristianos, México, 2. a ed., INAH, 1985, pág. 82 . 
México son los estados de Jalisco, Puebla y Oaxaca. En este último se denomina Danza de la Pluma, y está inspirada en una danza ritual precortesiana que recordaba la victoria de los mixtecos sobre sus vecinos zapotecos, antes de ser sometidos ambos pueblos por los aztecas, y que todavía se representaba a mediados del siglo XVII (8).

Consta que los episodios de la Conquista de México también se representaban ritualmente en fiestas de Panamá y Guatemala (9).

\subsection{Ciclo Quiché}

El baile de la Conquista está considerado «uno de los más interesantes y sugestivos exponentes del folklore guatemaltecon (10). De las respuestas a una encuesta oficial enviada a las municipalidades del país en 1970 se obtiene que por entonces se representaba el baile de la conquista en 69 localidades, los moros y cristianos en 48, y otras obras emparentadas en 7 (11).

Las acciones que se representan en estos bailes encajan con el testimonio que el conquistador Pedro de Alvarado envió por escrito a su jefe Hernán Cortés. Los funestos presagios y visiones del rey Quiché se pueden equiparar con las profecías sobre la llegada de terribles extranjeros "hijos del sol» de Los Libros de Chilam Balam (12), mientras que el duelo entre los capitanes Alvarado y Tecúm Umán es muy similar al descrito en los Títulos de la Casa Ixquin Nehaib, que se suponen redactados a mediados del siglo XVI (13). Queda así fortalecido el carácter de testimonio indígena «acerca de la llegada de los hombres de Castilla (...) que es la más viva recreación de los hombres blancos por las gentes del quiché», en palabras del ya citado León-Portilla (14).

(8) Demetrio E BRISSET: "Una familia mexicana de Danzas de la Conquista", Gazeta de Antropología, Granada, A.G.A., pág. 31.

(9) Bárbara BoDE: The dance of the conquest of Guatemala, Nueva Orleans, Tulane Univ., 1961, pág. 211: En Panamá se llamaba Los Montezumas y se representaba el día del Corpus; el Baile de Cortés guatemalteco está recogido en Cobán (Alta Verapaz) de un manuscrito de 1875.

(10) Jesús CASTRO: "El Baile de la Conquista", Guatemala Indigena, Guatemala, I.N.I., vol. 2, n 1, 1962, pág. 57.

(11) Encuesta a municipalidades sobre danzas. Guatemala, Dirección General de Cultura y Bellas Artes, 1971.

(12) LEÓN-PorTILla, 2, págs. 80-82.

(13) Ibidem, págs. 98-100.

(14) Ibidem, pág. 71. 


\section{ESTRUCTURA DEL BAILE DE LA CONQUISTA DE LOS QUICHÉS}

Estos bailes dramatizados suelen alternarse en la celebración de los santos patronos o titulares de las comunidades indígenas con otras danzas rituales, como las del venado, el torijo y los mexicanos. Su acompañamiento musical es monótono y cacofónico, basado en un tambor y una chirimía, mientras que en las otras danzas la marimba impone su alegre melodía.

En lo que respecta a la "producción" de estas danzas, apenas hay diferencias entre ellas. Una persona se ofrece para organizar y costear el espectáculo, siendo llamado «el autorn, y solicita la ayuda de un "maestro de danza" que tiene en su poder un texto de los parlamentos, para que ejerza la función de director a los jóvenes que se presentan para ser actores en cumplimiento de una promesa al santo. El vestuario, compuesto por muy elaborados trajes y máscaras de madera, se alquila por diez o catorce días a algunas de las "morerias» o almacenes de disfraces dedicados exclusivamente a esta actividad.

Los bailes de conquista tienen unos largos parlamentos, que se conservan en manuscritos que se suelen denominar Historia, Original, Relación o Libro. La investigadora Bárbara Bode consultó 29 de ellos -el más antiguo fechado en 1872- y constató que eran prácticamente iguales, pudiendo englobarlos en cuatro grupos, con sus variantes limitadas al personaje que inicia la obra y algunos trozos finales. "La escasez de variantes parece indicar que el pueblo no ha tenido acceso al drama escrito por mucho más de un siglo", derivando de un texto único cuyo autor fue "un hombre culto, conocedor de los hechos de la Conquista y de la tradición oral de los Quichés. Quizás imitara un anterior manuscrito de Moros y Cristianos, puso sus personajes en dos filas, añadió un gracioso, hizo alusiones clásicas y bíblicas y roció el texto con palabras cultas" (15).

Los personajes suelen ser 19, divididos en tres grupos:

- Españoles: D. Pedro de Alvarado (conocido como «tonatiuh» el sol, por su rubia barba); D. Francisco Carrillo, su lugarteniente; D. Pedro Portocarrero; D. Quirijol, un bufón ridículo; ...

- Indios: Tecúm Umán; caciques (Ixcot, Saquimux,...); Ajitz ("el brujo», que habita dentro de los cerros, con un hacha

(15) BodE, 9, págs. 224-225. 
pequeña y una muñeca - réplica de sí mismo-, quien efectúa actos de magia contra los invasores); Lacandón, un sirviente, indio salvaje del territorio mexicano.

- Familia real quiché: Rey Quiché; Príncipes $1^{\mathbf{0}}$ y $2^{\mathbf{2}}$; Malinches $1 .^{\mathrm{a}}$ y $2 .^{\mathrm{a}}$ (doncellas hijas del rey).

Los principales protagonistas del bando quiché son el valeroso caudillo Tecúm y el Rey Quicab, que de hecho vivió antes de la llegada de los españoles, y que en esta danza aparece como acobardado y débil, y termina como vasallo que solicita ser bautizado. Mientras, Tecúm lucha hasta su muerte contra el rubio Alvarado. Así se desdobla el personaje del jefe indígena, entre un rey anacrónico que acepta someterse, y un guerrero histórico que lucha sin cuartel, diciendo frases como: «arrostraré el peligro / con corazón denodado...". "Véte y dile a tu capitán / que no somos mexicanos; /que lo he de vencer con astucia / o a fuerza de buen soldadon. Las posturas de ambos son opuestas, y pueden reflejar el sentimiento colectivo ante el hecho de la invasión.

La guatemalteca Matilde Montoya sometió el argumento del baile a un análisis narrativo, encontrando un prólogo y veintitrés escenas prácticamente en todos los textos, considerando que la escena fundamental o decisiva es la décimo octava, que consiste en la batalla, con la lucha cuerpo a cuerpo entre Tecúm y Alvarado, quien le mata con la lanza que le da Portocarrero. Al interrumpirse entonces la batalla por decisión de Huitzitzil (heredero de Tecúm), los quichés determinan convertirse al cristianismo. Lamentaciones por la muerte de Tecúm se llevan a cabo por sus hombres, que disponen las honras fúnebres trasladando el cadáver al palacio del rey quiché (16). En algunas representaciones actuales termina aquí la obra.

Por mi parte, he aplicado un análisis morfológico al mismo argumento, siguiendo el método diseñado por W. Propp para el estudio de los cuentos maravillosos, con las correcciones necesarias por tratarse aquí de una obra teatral. Así, considerando como "funciones" a las acciones significativas en el desarrollo de la representación teatral, he encontrado una unidad estructural

(16) Matilde Montoya: Estudio sobre el Baile de la Conquista, Guatemala, Ed. Universitaria, 1970, en su cap. "Análisis filológico". 
entre las obras de Moros y Cristianos, las Danzas de la Conquista y las restantes representaciones rituales de conquista (17).

En el caso específico del baile de conquista guatemalteco, de acuerdo con este análisis argumental se obtiene la siguiente secuencia "sintagmática»:

Introducción: Rey Quiché se entera de la llegada de los Españoles.

Desarrollo de las acciones:

1. Los quichés reciben un comunicado de parte de los aztecas $(Q$ = comunicado).

2. Sueño con malos presagios para los quichés $(V=$ sueño o visión presagiosos).

3. Debate interno entre los quichés.

4. Súplica de los españoles a su Dios.

5. Reto de los españoles.

6. Nuevo debate interno en el campo de los quichés.

7. Nuevas visiones funestas entre los quichés.

8. Batalla por la fe religiosa, con victoria de los españoles.

9. Muerte de un quiché.

10. Conversión de parte de los quichés.

11. Entierro del quiché muerto.

12. Negociaciones entre ambos bandos.

13. Otra versión entre los quichés.

14. Conversión del resto de los quichés.

\section{PRECEDENTES HISTÓRICOS DEL BAILE DE LA CONQUiSTA}

Para el abate Brasseur, los bailes prehispánicos de los mayas se podían clasificar de acuerdo con las siguientes categorías:

«Areitos»: simples danzas con cánticos.

«Mitotes»: danzas con recitaciones.

«Danzas completas»: con música, baile, diálogos y empleo de máscaras (18).

(17) Demetrio E. BRISSET: Representaciones rituales hispánicas de conquista, Madrid, Univ. Complutense de Madrid, 1988, cap. 3.

(18) María de Baratta: Cuzcatlán típico. Ensayo sobre etnofonía de El Salvador, San Salvador Min. de Cultura, 1952, t. I, pág. 71. 
A los pocos años de la conquista del imperio quiché, el Ayuntamiento de la capital Santiago de Guatemala dispone en 1538 que usalgan de fiesta en la procesión del Corpus como se usa en los Reynos de España» (19). En 1541 llegan los primeros frailes franciscanos, encabezados por fray Toribio de Benavente, llamado Motolinia en México, quienes emprenden la tarea de evangelizar a los indígenas, fundando conventos como el de Santiago Atitlán en 1544. Ya habían utilizado con buenos resultados entre los mexicas el método de sustituir el fondo pagano de sus fiestas por otro católico (20).

Fue $\tan$ efectiva la labor de los misioneros franciscanos y dominicos, que en 1575 escribía un cronista que en la zona central de Guatemala, "de los ritos y costumbres antiguos de estas gentes, de su religión y fiestas y regocijos y juegos $\mathrm{y}$ ceremonias en los casamientos, cazas y pescas, y de las muchas supersticiones que tenían no hay que decir porque por la misericordia de Dios y beneficio de la cristiandad ya no hay memoria ni rastro de nada; solo les han quedado sus bailes antiguos en las fiestas pero con cantos y palabras cristianas y devotas" (21). Esta opinión se ha revelado ser de un triunfalismo desorbitado, fomentado por el disimulo con el que los indígenas conquistados enmascaraban sus antiguos cultos bajo los nuevos ropajes evangélicos.

Un ejemplo de antigua celebración festiva transformada, para adecuarla al gusto de los dominadores, es el de la Fiesta del Volcán, que desde fines del siglo XVI se representaba en Antigua con el nombre de Peñol de los indios, conmemorando la batalla de 1526 en la que Portocarrero capturó a los cabecillas rebeldes Sinacam y Sequechul, quienes se habían refugiado en una montaña. Para el espectáculo ritual se construía una montaña artificial en una plaza, con abundancia de animales y vegetación en sus laderas, y la casa del rey indio en la cumbre. Cientos de indios disfrazados con ropajes prehispánicos representaban las tropas rebeldes, que se enfrentaban en escaramuzas contra el bando de

(19) G. Mejía Ruiz: "Las fiestas populares del Corpus en Guatemala", Tradiciones de Guatemala, Guatemala, n VIII, 1977, pág. 14.

(20) Francis B. STECK, O.F.M.: Motolinia's History of the Indians of New Spain, Washington, 1951, pág. 23: El P. Motolinia estuvo encargado desde 1540 del aprendizaje de los futuros misioneros a Guatemala, en el convento de Tlaxcala. En 1543 realizó su tercer viaje a las misiones de Guatemala, permaneciendo durante quince meses alli. Había sido llamado por el primer obispo de Guatemala. D. Francisco Marroquín, quien le propuso para el cargo de obispo de Yucatán.

(21) Francisco MonTERo: "Descripción de la Provincia de la Verapaz", Anales de la Sociedad de Geografía e Historia, XXVII, marzo 1953, pág. 357. 
los "españoles", compuesto por descendientes de los indios mexicanos - que acompañaron a Alvarado-, vestidos a la usanza de la metrópoli. Este espectáculo, que parece estar inspirado en ceremoniales de culto a los espíritus de los volcanes, similares a los que se hacían en el México precortesiano, durante el siglo XVIII era llamado "el peñol de la conquista" y se dejó de representar alrededor de 1780 debido a su excesivo coste. Curiosamente, en Rabinal hasta hace una década se construía una montaña artificial muy elaborada, similar a la anterior, para servir de escenario a la representación del baile de la conquista, mientras que en otras localidades el catafalco en el que llevan a enterrar al personaje del Tecúm Umán muerto tiene forma de volcán (22).

Un eslabón clave en la génesis de estos bailes puede ser el Rabinal Achi. El abate Brasseur de Boubourg, párroco del mencionado Rabinal, asistió en 1855 a la representación de lo que él calificó como baile-drama prehispano, con un texto en achí antiguo que ya no se entendía, y que reflejaba una situación histórica vivida por los habitantes de Rabinal en conflicto territorial con los vecinos quiché. Los personajes eran el rey Jobtoj de Rabinal, el varón de Rabinal y sus respectivas esposas, el varón quiché, una sirvienta, guerreros-águila y guerreros-tigre (23). Su argumento «relata el cautiveron del varón de los Quiché en tierras del varón de Rabinal. Pide varias gracias antes de ser sacrificado y en la última, danzar con los Caballeros Águila y los Jaguares, que le derrotan" (24). Aunque algo simplificado en el número de personajes, este baile-drama todavía se representó en 1983, conservándose el mismo temor por parte de los danzantes a sufrir penalidades en caso de no cumplir con las "costumbres" o ritos preceptivos de solicitar permiso y protección con ofrendas presentadas por el «abogado" o anciano rezado a las divinidades de los montes, almas de los difuntos, Santa Tierra y Dios.

Los instrumentos musicales utilizados son dos trompetas y un tambor o "tun», que le proporciona el otro nombre con el que es conocido: baile del tun. En cuanto a la esposa del varón de

(22) Carroll E. MACE: Two spanish-quiché dance-dramas of Rabinal New Orleans, Tulane Univ., 1970, págs. 39-40. Esta localidad se encuentra precisamente en la Alta Verapaz, la provincia en la que el cronista Montero daba por desaparecidos los antiguos cultos ya en el XVI.

(23) Francisco R. ROUANET: “Notas sobre una representación actual del Rabinal Achí o Baile del Tun", Guatemala Indigena, vol. 2, n 1, 1962, pág. 48.

(24) Montoya 16, pág. 24. El escenario simula ser una fortaleza. 
Rabinal, la princesa, estaba a cargo de una niña de diez años alhajada con un collar de cuentas de plata y un pañuelo que le cubre la cara.

\section{ETNOGRAFía ACTUAL DEL BAILE EN GuATEMALA}

La presente información fue recogida en una campaña de trabajo de campo efectuada en el verano de 1989. Dividiremos la exposición por zonas geográficas.

\section{El quiché}

\subsection{Joyabaj, 8-15 de agosto, Virgen de la Asunción.}

En la plaza principal de la localidad tiene lugar un animado mercado. En el centro, un árbol volador, un elevado poste del que los "voladores" descienden girando una y otra vez, mientras que en el suelo varios «micos» hacen sus gracias. Por las esquinas y los laterales de la plaza se forman amplios corros en torno a los componentes de las diversas danzas, que actúan disfrazados en honor de su virgen titular o patronal. Simultáneamente se oyen la música de las danzas del Venado, del Torito y de la Conquista, que se representan en el suelo sin ningún tipo de decorado. El público permanece atento, deambulando de una a otra danzas, con una actitud de máximo respeto.

El bando de los españoles del baile de la conquista estaba caracterizado con chaquetas militares de gala, tricornios emplumados, espadas al cinto y máscaras de blancos con bigotes rubios y expresión malhumorada, cubriendo los ojos con gafas de sol, y enarbolando uno de ellos la bandera rojigualda. El bando de los quichés vestía adornadas telas de fieltro, con una especie de casco-corona emplumado que culmina en una media luna - llamado "castillo»-, máscaras negras con bigote negro y un pájaro de madera en la mano. El personaje de Tecúm se cambia tres veces de máscara, mientras que el brujo Ajitz y su pequeño ayudante visten de rojo con máscaras también rojas. Finalmente, el bando de la Familia Real se componía del Rey Quiché - con la bandera nacional guatemalteca en la mano-, el pequeño Príncipe (ambos con rostros como los de los españoles) y la niña -Malinche-, con su rostro cubierto por un pañuelo. 
La representación dio inicio con un baile que sirvió de prólogo durante más de media hora, con el bando Quiché, la Familia Real y un par de Españoles (los Embajadores), mientras Alvarado y Portocarrero descansan en sillas. Un tambor y una flauta imprimían un ritmo serio y reiterativo, roto por las continuas bromas y persecuciones de los antagonistas burlescos (Ajitz y el brujo pequeño y $\mathrm{D}$. Quirijol con su ayudante) que se convertian en el centro de atención con sus disparatadas peleas, en las que siempre salían perdiendo y huyendo los dos españoles. La obra en sí comenzó con las palabras con las que el rey quiché apercibía a sus familiares de la entrada de los españoles en su reino. La falta de orificios en las grandes máscaras de madera, unido a la ronquera producida tras varios días casi ininterrumpidos de actuaciones, hacía que apenas se entendiesen los diálogos, incrementándose esta dificultad por el estruendo causado en la plaza por el volumen de los altavoces de una noria. Lentamente se fueron desgranando las escenas, con el cautiverio de los dos Embajadores españoles, que atados y amordazados eran paseados ante el público que se reía de las bromas pesadas que los dos brujos descargaban sobre ellos; las discrepancias y temores entre algunos miembros del bando quiché; la gallardía y valor de Tecúm. Hasta desembocar en la batalla final, en la que Alvarado clava su lanza en Tecúm, quien es llorado por los suyos que lo introducen en un ataud y se lo llevan, terminando así la representación unas seis horas después de su inicio. Y nada más concluir, en un espacio cercano otro grupo de danzantes, vestidos casi del mismo modo, aunque en este caso sin las gafas de sol por parte de los españoles, comenzó su actuación. Mucho público, en su mayoría niños y jóvenes, siguieron atentamente el idéntico desarrollo de las acciones, mientras los voladores seguían subiendo y bajando del alto mástil y los otros grupos de danzantes continuaban sus hipnóticas evoluciones.

\subsection{Santo Tomás Chichicastenango, 17-26 Diciembre, Santo Tomás.}

Última representación del Baile de la Conquista en 1984.

D. Diego Ignacio Nix, escultor de máscaras, 42 años, maestro de danzas y «sajorin» o sacerdote indígena, informa lo siguiente:

«El Baile se hace por devoción o petición que se tiene que cumplir. Si se ha organizado una vez, hay que repetirlo 
hasta siete veces, aunque no es necesario que sean consecutivas. El "autor" debe correr con los gastos (música, bombas, comida, bebida, vestuario), aunque el coste de algunos de los ensayos - de tres días de duración cada uno- se reparte entre los "vasallos" o miembros del grupo. Cuando alguien quiere organizar el baile, llama a un maestro y lo contrata por un quetzal y un trago de licor. Se pone uno de acuerdo con su esposa y se compromete a desempeñar ese cargo. Luego se tiene que cumplir con la devoción, porque si no puede morirse un niño, uno mismo, un animal, salir mal un negocio. La primera de las costumbres es que el autor y un sajorin suban a hacer una ofrenda a Pascual Abaj (25), unos quince días antes del primer ensayo, para que no haya ningún elemento que se retire, ya que no se firma ningún contrato».

"Todas las fechas se eligen entre las que el calendario maya designa como favorables. Durante los ensayos, un sajorín permanece en una habitación con imágenes de los santos, y bendice a los que llevan la masa de maíz para cada comida. Luego, cada actor tiene que buscar su sajorín propio para hacer sus costumbres, especialmente en la cofradía. Hay que evitar que los encantos o espíritus no estén descontentos, nadie sabe cuantos hay. Cuando llega la fiesta titular, se hacen tres bailes cada día, unas quince horas de bailar sin parar, comenzando y terminando en casa del autor, y pasando por las casas donde se guardan los santos, las iglesias, la casa del alcalde de sacristía y la procesión del día 21. En cada cofradía se da una jícara de atol (maíz, cacao, pepitas de zapote) caliente y espeso a cada bailaor".

"Cada cofradía se compone de seis u ocho miembros, las más antiguas tienen seis: alcalde, $2^{\circ}$ alcalde, tesorero, $4^{\circ}$ alcalde, $5^{\circ}$ alcalde y $6^{\circ}$ alcalde. Los mensajeros buscan flores, pino, limpian la casa y si no hay agua potable la van a buscar. El primer alcalde es el dueño de la casa, y si no, la alquila. La principal, la de Santo Tomás, tiene una carnicería propia. El primer alcalde pone cerca de 1.000 quetzales, y lo que se obtiene de ganancia se invierte en mejoras de la imagen. Al primer alcalde se le libera de otros servicios para que se dedique a cuidar la imagen. En otras

(25) El "Pascual Abaj" es un ídolo de piedra prehispánico, muy venerado en la comarca de Chichicastenango. 
cofradías se van turnando cada semana en la atención del culto. Los cófrades (sic), son elegidos por medio de la Auxiliatura Indígena del Ayuntamiento. El autor tiene que ser independiente de la cofradía, tiene que hacer gasto para cumplir con su devoción. En 1989 se harán cuatro Bailes del Torito y uno de Mexicanos*.

«Respecto al motivo para seguir haciendo el Baile de la Conquista, es por darles a los hijos demostración de la devoción que uno debe cumplir para tener buenas cosechas y buenos negocios. La imagen no da dinero, pero puede ayudar a que con su trabajo uno tenga ganancias. No duele recordar la derrota. Nadie vio cómo fue esa Conquista. Es una leyenda que llevamos dentro. Nadie les conoció. Rey Quiché y Ajitz son encantos, pero nadie sabe dónde se encuentran. Ajitz se aparece a las personas que tienen malos pensamientos, y el Rey no se sabe si es positivo, pero dicen que existe».

\section{Lago Atitlan}

En el siglo XVII existían tres conventos franciscanos en las orillas del lago, compartido por grupos étnicos quichés, cakchikeles y tsutuhiles. Había predicadores doctrineros que dominaban las tres lenguas, en los conventos de Santiago Atitlán (el más importante), San Pedro de la Laguna y San Francisco Panajachel (26). Actualmente son diez las poblaciones del lago que conservan o recuerdan el Baile de la Conquista.

\subsection{San Pedro la Laguna, 29 de junio, San Pedro}

Última representación en 1986. Se dispone de dos informaciones, relacionadas entre sí.

Feliciano Pop, escultor, 62 años, alcalde electo en 1986, detenido por sus actividades políticas durante 17 meses:

(26) Francisco Vázouez, "Crónica de la provincia del Santísimo Nombre de Jesús de Guatemala" (hacia 1680), en Guatemala Indigena, I.N.I., vol. IV, ${ }^{\mathrm{Q}} 1$, 1968, pp. 32-33, reproduciendo el capítulo XXXIV del libro. Más adelante explica que: "La práctica en enseñarles la doctrina, predicarles y administrarles es la misma que se tiene en toda la provincia, asistiéndoles con toda vigilancia y conservarlos en la buena educación que han tenido como buenos cristianos" (pág. 38). 
«En 1946 nos quedamos sin el Baile. Los enemigos, por la religión, quitaron las costumbres. En 1986 llegué a la alcaldía a presentar mi Baile. Pedí prestado el libro, con su relación; cada bailador sabe qué significa. Cada uno tiene a su cargo zapatos, calcetines y pañuelos, y pagar los gastos del viaje para alquilar los trajes. El resto de los gastos los pagué yo, perdí más de 3.000 quetzales. Me interesa mucho la Conquista: es el único baile que ha traído la paz de Dios a este mundo. En el Baile de la Conquista viene el primer bautismo, cuando Pedro de $\mathrm{Al}$ varado bautizó a todos los reyes y trajo la doctrina y toda la civilización. Tecúm era el único rey, no era culpable, lo matan inocentemente, era muy inteligente, enseñó el arte; si no le hubieran matado aquí seríamos los mejores fabricadores de oro y plata. El rey Quiché es superior, le manda como un dios, es viejito, por eso la máscara es blanca.

"La costumbre antes era, al empezar el baile, ir en busca del brujo, que lleva candelas, incienso y trago, con todos los bailadores, a los barrancos. Aquí lo hacemos en la casa de ensayos, pedazos de tejas con velas, una por cada actor, para que no muera. Es un baile muy peligroso, si uno no respeta sus costumbres, muere. Los reyes existen ahora en las montañas, aquí en el lago hay algunas. Por eso lo prohibieron los que tienen religión; "es el diablo" dicen, pero desde la creación del mundo han venido. Estuve dos veces de bailador, mi finado padre fue el "principal" del pueblo, y su casa fue casa de cofradía. El día de la fiesta se reúnen a las 7 . A las 8 se van frente a la iglesia y están todo el día, hasta las 6 de la tarde, bailando sin parar. De dos en dos salen a comer sus raciones. No se puede parar el baile si hay público. Y sin trago, se mira feo si un bailador es "bolo" (borracho). El más peligroso es Ajitz, unos veinte días antes ya no duerme en su casa, tiene mucha responsabilidad. El del último baile tenía 40 años. Las edades de los bailadores variaban entre los 60 años, Tecúm y Zunun, y los 15 del Príncipe y los 12 de la Malinche, la "patoj» (doncella). En la procesión, delante de San Pedro va el baile».

D. Pedro Cruz; profesor, jornalero y cantero, 46 años, secretario general del F.U.R. en Sololá:

"Cuando Feliciano estuvo de alcalde, organizó un grupo de teatro de folklore y me nombraron director del grupo. 
Mi intención es respetar el costumbrismo. Aquí ya no existen cofradías, ni el respeto, como besar la mano a las mujeres. Como artista que soy voy a tratar la forma de presentar a la juventud de hoy como se hacía antes. Estoy tratando de rescatar el traje típico para mi grupo. Y tener actuaciones, para que la juventud no se envicie».

«El cuaderno del baile se titula Historia de Tecum Umán. El Baile de la Conquista refleja la cultura de todas las regiones indígenas, parte de nuestras costumbres que hemos perdido, antes las cofradías hacían estas costumbres. El libro quedó sin tocar desde hace más de 40 años. Sus hijos nos dieron papeles viejos del difunto dueño, yo lo copié en limpio y lo estoy utilizando ahora. A mí me buscan ahora por tener esta historia de antiguo. Aquí se hacía antes todos los años, ahora se hace con mucha seriedad, formando un comité, que sea cosa de calidad. Feliciano quiere volver a sacarlo dentro de dos años».

\subsection{Santiago Atitlan, $24-25$ de julio, Santiago Apóstol}

Última representación en 1975. D. Alfonso Choy, técnico de radio, 40 años, autor del baile del Corpus:

«El primer cófrade de la cofradía de Santiago va a casa del autor a pedirle si presenta baile; si se negara, van a buscar otro. El actual llevará su cuarto año organizándolo, este año hizo el de Mexicanos, y el próximo hará el de Conquista. Se es autor por devoción, es una promesa, para enseñar un poco a mis hijos cómo soy yo y cómo es nuestro pueblo, y recordar a nuestros padres. Es un bien».

\subsection{San Marcos la Laguna, 25 de Abril, San Marcos}

Última representación en 1982. D. Santos Quiacain, agricultor, 49 años, autor $1^{\mathbf{o}}$ :

«Fiesta será con Baile de Conquista este año, ya repartidos papeles, ensayo primero se ha hecho. Son 25 bailadores, repiten muchos de la vez anterior. Yo, el autor, doy cuenta de lo que necesitan. Lo hacemos por la fiesta de San Marcos, gusta ver visitantes de lejos, cada año se varía el 
baile. Baile de Conquista es la misma historia, no hay cambio. Tecúm muere pero puede revolver. Igual historia quiché que cakchiquel».

\subsection{Panajachel, 4 de Octubre, San Francisco.}

Última representación en 1986. D. Ventura Churumel, comerciante, 64 años, autor y cófrade:

«Somos cuatro personas las encargadas de la cofradía desde hace cinco años, porque nadie lo quiere. El año pasado hicimos el Torito, éste Mexicanos, si Dios quiere, Conquista se hará de nuevo el próximo año. Gusta que sea un baile distinto cada año. La ropa está muy cara. No se juntan mucho los muchachos. Me ayudan mi hijo y un amigo de él. Tenemos que hacer una costumbre.

De la Conquista, muy bonitos los trajes».

2.5. Santa Cruz la Laguna, 3 de mayo, Santa Cruz.

Última representación en 1984. Con dos informaciones. D. Juan Andrés Pérez, agricultor, 65 años, Auxiliatura municipal:

"Antes se hacían costumbres en las fiestas, ahora ya no consiguen "pisto" (dinero), no quiere la gente. Protestantes se burlan de los católicos: ¿Por qué gastan "pisto"? Jóvenes no quieren, no les gusta. Ya se terminó la fiesta. Antes, sí alegre».

D. Andrés Chial, agricultor, 74 años, siendo alcalde fue el autor de la última representación de la Conquista:

"Era mucho "pisto". Si se encuentra "pisto", volvería a hacerse. Baile de Conquista es historia, como soy cakchiquel me da gusto. Hice tres veces de Pedro de Alvarado de España. A Tecúm Umán le van a matar, esa es la historia. Lo que manda la historia, eso van a hacer».

2.6. San Jorge la Laguna, 23 de Abril, San Jorge.

Última representación en 1952. D. Vicente Ramos, agricultor, 67 años, alcalde: 
"Ya no se hace la Conquista, está caro el tiempo, todo cuesta mucho. Un particular pedía permiso a la alcaldía, piensa bailar y tiene su licencia. El autor del baile busca un maestro que va enseñar. Uno busca compañia, y cuando aceptan los demás, hacen ensayos. Son puro voluntario. Se juntan quince o veinte y reúnen "pisto" para los trajes.

Baile de la Conquista es lindo, dan ganas de bailar. Tienen que ir a la iglesia, pedir perdón, que no va a pasar nada. Sólo eso, a la montaña no se va. En cakchique, Baile de la Conquista se llama "Shajob Tecum".

\subsection{San Pablo la Laguna, 25 de Enero, San Pablo.}

Última representación en 1988. En 1990 no habrá ningún baile: «No les gusta bailar» (Inf. anónimo).

2.8. También se hacía el Baile de la Conquista en: Santa Lucía y Santa Clara la Laguna, sin datos, aunque como las fiestas siguen el calendario eclesiástico, los días patronales son el 13 de diciembre y el 11 de agosto respectivamente.

Había una "morería» en Solola, la cercana capital de la provincia.

\section{SACATEPEQUEZ}

San Miguel Dueñas, 8 de Diciembre, Inmaculada Concepción.

Última representación en 1988 (anteriormente, solamente en 1955 y 1967. D. Genaro Vega, oficial de panadería, 47 años, maestro de danzas:

«En la fiesta, cada año se cambia de baile. Ahorita no sé cual se hará este año. En los años pasados se hicieron los bailes de las Flores, Fierabrás, los Negros, Mexicanos, la Región, las Piedras, la Reina Catalina y Filomena, los Animales. La Hermandad me pide colaboración y yo dispongo qué baile puedo organizar. Nadie me paga. La Hermandad paga el tambor y otros gastos. Las máscaras, espadas, plumajes, son alquilados y se pagan individualmente. El cura no tiene nada que ver".

«Para el Baile de la Conquista, el pasado año, seleccioné los actores según su voz, como llevan máscara, da igual la 
edad. No tienen máscara los dos Príncipes y las dos Malinches (dos señoritas). Los más altos de cada bando hacían de Alvarado, Quiché y Tecúm. Gusta que se diga cómo está escrito: si se hacen improvisaciones, pierde. Para la presentación del baile se hace un volcán de madera forrado de musgo, de unos dos metros y medio, que sirve de sepulcro a Tecúm. Ahí lo meten cuando lo llevan a sepultar. La misma relación lo dice: «quien murió por la patria». Se hicieron trajes nuevos y máscaras. Los visitantes compraron las máscaras. Este baile son historias vividas y todo el mundo sabe lo que contienen. Se volverá a organizar dentro de diez o quince años, hay un montón de bailes. El personal no puede ser el mismo, uno no tiene la vida comprada».

\section{Quezaltenango}

4.1. Almolonga, 29 de junio, San Pedro.

El último Baile de la Conquista se representó hace tiempo. D. Pedro Silva, agricultor, 45 años, autor:

«Este año fui autor del Baile de Moros, con Oliveros y Fierabrás. Los trajes son como los de la Conquista, con máscaras de españoles todos, corona con la media luna los moros y sombrero los cristianos, ambos con plumas de colores y grandes capas. Van a caballo, y la batalla es con espadas. La gente está poco interesada en que salga una fiesta alegre. Se les invita, pero no aceptan".

\subsection{Olintepeque}

Última representación en 1984.

5. OTRAS LOCALIDADES CON REPRESENTACIÓN ACTUAL

Santa Bárbara Huista, Huehuetenango, 22-24 de Agosto.

Aldea Chicol, Huehuetenango, 22-24 de Agosto.

Tacana, San Marcos, 12 de Agosto.

San Bartolo, Totonicapan, 20-25 de Agosto.

San Bartolomé Jocotenango, El Quiché, 22-24 de Agosto. 
CONCLUSIONES FINALES

Entre las variantes latinoamericanas de las Representaciones Rituales de Conquista se encuentran las Danzas de la Conquista, con las que numerosas comunidades indígenas del centro de México, los Altos de Guatemala y los Andes centrales, recuerdan los episodios de la llegada de los Españoles y el modo en el que fueron sometidos sus antepasados. Este tipo de drama ritual tuvo precedentes en los ceremoniales prehispánicos, y desde el siglo XVI se fue desarrollando como espectáculo popular en las fiestas coloniales.

Respecto al ciclo quiché, o Baile de la Conquista en Guatemala, es uno de los bailes rituales con los que se honra a los santos titulares de muchas comunidades indigenas, en relación con las "cofradías" de los santos a cargo del "autor" que lo costea, con un "maestro" que lo enseña a los actores que se ofrecen para cumplir con sus promesas al santo. Los parlamentos de este baile teatralizado apenas varían entre sí, y comparten la misma estructura narrativa que las obras de Moros y Cristianos, que se puede reducir a una secuencia de 14 "funciones" significativas. El empleo en las fiestas de la España de los Austrias como modelo y la labor de los misioneros franciscanos contribuyeron a la transformación de ciertos rituales, como la Fiesta del Volcán, en Bailes de la Conquista. El Rabinal Achí, drama prehispánico descubierto a mediados del siglo XIX y representado todavía en nuestros días, puede ser un eslabón-clave en el proceso de metamorfosis formal.

Los datos etnográficos recogidos personalmente en 1989 ilustran la visión con la que este baile ritual es percibido entre sus organizadores: su carácter sagrado, para aplacar y obtener la benevolencia de los poderosos "encantos" que habitan en el interior de montañas y volcanes; su función como recordatorio de las antiguas costumbres. No duele para los descendientes de los vencidos revivir su derrota: la Historia manda; finalmente, la falta de dinero y de interés por los jóvenes, así como la expansión de las ideas protestantes, están contribuyendo a su paulatina desaparición. 